\title{
Multimodal analgesia model to achieve low postoperative opioid requirement following bariatric surgery
}

\author{
Katherine KY Lam *, Wilfred LM Mui
}

\section{A B S T R A C T}

Objective: To investigate whether a new anaesthesia protocol can reduce opioid use in obese patients following laparoscopic sleeve gastrectomy.

Methods: This prospective observational case series was conducted in a private hospital in Hong Kong that has been accredited as a Centre of Excellence for Bariatric Surgery. Thirty consecutive patients scheduled for laparoscopic sleeve gastrectomy from 1 January 2015 to 31 March 2015 were reviewed.

Results: Of the 30 patients, 14 (46.7\%) did not require any opioids for rescue analgesia during the entire postoperative period; six $(20.0 \%)$ required rescue opioids only in the post-anaesthetic care unit, but not in the surgical ward. The mean postoperative

This article was published on $15 \mathrm{Jul}$ 2016 at www.hkmj.org. total opioid requirement per patient was $32 \mathrm{mg}$ of pethidine.
Conclusion: With combination of multimodal analgesia with local anaesthetic infiltration, it is possible to avoid giving potent long-acting opioids in anaesthesia for bariatric surgery.
Hong Kong Med J 2016;22:428-34
DOI: $10.12809 / \mathrm{hkmj} 154769$
KKY Lam *, FHKCA, FHKAM (Anaesthesiology)
WLM Mui, FCSHK, FHKAM (Surgery)
Hong Kong Bariatric and Metabolic Institute and Evangel Hospital Weight Management Centre, Room 610, Champion Building, 301-309 Nathan Road, Jordan, Hong Kong
* Corresponding author: katherinelamky@gmail.com

\section{New knowledge added by this study \\ It is possible to avoid giving potent long-acting opioids in anaesthesia for bariatric surgery, by using multimodal analgesia with a combination of paracetamol, pregabalin, COX-2 inhibitors, tramadol, ketamine, dexmedetomidine, and local anaesthetic wound infiltration. \\ Implications for clinical practice or policy \\ - The use of this opioid-sparing anaesthetic technique can potentially reduce the adverse effects and morbidity associated with the use of opioids in obese patients. The technique can be extended to other types of surgery in obese patients.}

\section{Introduction}

Obese patients are particularly sensitive to the sedative and respiratory depressive effects of longacting opioids. Many obese patients also have obstructive sleep apnoea syndrome (OSAS) and will be prone to airway obstruction and desaturation in the postoperative period, especially if opioids have been given. ${ }^{1,2}$ Given this background, multimodal analgesia is advocated for bariatric surgery with the aim of reducing opioid use. ${ }^{3,4}$ At the time of writing, no studies were able to demonstrate a technique that can consistently remove the need for any postoperative opioid analgesia. In this study, we report the use of an anaesthesia protocol that allowed a significant proportion of our patients undergoing laparoscopic sleeve gastrectomy to be completely free from any long-acting potent opioids in the intra-operative and postoperative period.

\section{Methods}

\section{Patient selection}

This was a prospective observational study. The study was conducted in a private hospital in Hong Kong that has been accredited as a Centre of Excellence for Bariatric Surgery. All patients scheduled for laparoscopic sleeve gastrectomy for management of obesity or type 2 diabetes from 1 January 2015 onwards were anaesthetised using the same protocol. We analysed 30 consecutive cases between 1 January 2015 and 31 March 2015 to investigate the postoperative opioid requirements using this anaesthesia protocol. Patients were excluded from the case series if they had contraindications or allergy to any of the anaesthetic or analgesic drugs, or if anaesthesia deviated from the standard protocol for any reason. Three patients were excluded-one was taking serotonin-specific 
reuptake inhibitor antidepressants and pethidine was avoided to prevent serotonin syndrome (morphine given instead); one was allergic to nonsteroidal anti-inflammatory drugs (NSAIDs), so intravenous parecoxib and oral etoricoxib were not given; one accidentally had a larger dose of ketamine given intra-operatively than allowed by the protocol. Concomitant laparoscopic cholecystectomy was performed with laparoscopic sleeve gastrectomy in three patients who were included in the study.

\section{The anaesthesia protocol}

All patients were fasted from midnight on the night before surgery. All operations were scheduled in the morning. Patients were premedicated with oral pantoprazole $40 \mathrm{mg}$ on the night before surgery, and $2 \mathrm{~g}$ of oral paracetamol and $150 \mathrm{mg}$ or $300 \mathrm{mg}$ of oral pregabalin (for patients of body mass index $<35 \mathrm{~kg} / \mathrm{m}^{2}$ or $\geq 35 \mathrm{~kg} / \mathrm{m}^{2}$, respectively) 2 hours before surgery.

Upon arrival in the operating theatre, intravenous access was established and 1 to $2 \mathrm{mg}$ of intravenous midazolam was administered followed by an infusion of dexmedetomidine. The dose of dexmedetomidine was titrated according to the calculated lean body weight (LBW) using the Hume formula. ${ }^{5}$ The starting dose of the dexmedetomidine was $0.2 \mu \mathrm{g} / \mathrm{kg} / \mathrm{h}$ using LBW. ${ }^{6}$ No loading dose was given.

Standard monitoring was applied to the patient together with a bispectral index (BIS) monitor and peripheral nerve stimulation monitor. Graduated compression stockings and sequential compression devices were used for all patients. Induction of anaesthesia was accomplished with fentanyl $100 \mu \mathrm{g}$, a titrated dose of propofol, and either suxamethonium or rocuronium as appropriate. The trachea was intubated and patients were ventilated with a mixture of air, oxygen, and desflurane.

Intra-operatively, desflurane was titrated to maintain BIS value between 40 and 60. Muscle relaxation was maintained with a rocuronium infusion to keep a train-of-four count of 1 . Dexmedetomidine infusion continued at $0.2 \mu \mathrm{g} / \mathrm{kg} / \mathrm{h}$ or higher if necessary. Shortly after induction, the various supplementary analgesic drugs were given. A loading dose of ketamine $0.3 \mathrm{mg} / \mathrm{kg} \mathrm{LBW}$ was given followed by intermittent boluses roughly equivalent to 0.2 to $0.3 \mathrm{mg} / \mathrm{kg} / \mathrm{h}$ of LBW. Intravenous parecoxib $40 \mathrm{mg}$ and tramadol $100 \mathrm{mg}$ were given. Dexamethasone $8 \mathrm{mg}$ and tropisetron $5 \mathrm{mg}$ were given intravenously for prophylaxis of postoperative nausea and vomiting (PONV).

For intravenous fluids, patients were given 10 $\mathrm{mL} / \mathrm{kg}$ actual body weight of either lactated Ringer's solution or normal saline, then more were given as appropriate. Hypotension was treated with either ephedrine or phenylephrine.

\section{使用多模式鎮痛法以減低減重手術後嗎啡類鎮痛 藥的用量 \\ 林嘉儀、梅力文}

目的：探討一個新的麻醉模式能否減少肥胖患者在接受腹腔鏡縮胃手 術後對嗎啡類藥物的用量。

方法: 本前瞻性觀察病例研究於香港一間私家醫院進行, 這醫院已獲 減重手術卓越中心國際認證。研究對象為2015年1月1日至3月31日期 間所有在上述醫院接受腹腔鏡縮胃手術的30名患者。

結果：患者中 14 人（ $46.7 \%)$ 在整個術後階段均冊須使用任何嗎啡類 鎮痛藥；6人 $(20.0 \%)$ 僅在術後麻醉護理病房期間需要嗎啡類鎮痛 藥, 回到外科病房後則無此需要。每名患者術後使用嗎啡類藥物的平 均總劑量為32毫克杜冷丁。

結論：在減重手術的麻醉中使用多模式鎮痛法併合局部麻醉, 可以避 免術後處方長效嗎啡類藥物的需要。

When the surgeon started to close the wounds, rocuronium infusion was stopped and dexmedetomidine infusion rate was reduced to $0.1 \mu \mathrm{g} / \mathrm{kg} / \mathrm{h}$. Wounds were infiltrated with $20 \mathrm{~mL}$ of $0.5 \%$ levobupivacaine. When all wounds were closed, dexmedetomidine infusion was stopped and desflurane switched off, muscle relaxation reversed by neostigmine and atropine. Patients were extubated when awake and able to obey command.

After extubation, patients were transferred to the post-anaesthetic care unit (PACU) for observation for 30 minutes, or longer if appropriate. If a patient required rescue analgesia, intravenous pethidine $20 \mathrm{mg}$ with intravenous ketamine $5 \mathrm{mg}$ was given, and the dose repeated if necessary. When $10 \mathrm{mg}$ of intravenous ketamine had been given, further rescue analgesia was intravenous pethidine $20 \mathrm{mg}$ without any more ketamine. This avoided administration of too much ketamine in an awake patient causing dizziness or hallucinations. When patients had good pain control and stable vital signs, they were transferred back to the ward. The standard postoperative protocol was initiated: if patients requested analgesics, an intramuscular injection of pethidine $50 \mathrm{mg}$ was given, and repeated after 4 hours if necessary. By early evening, when vital signs were stable, patients were allowed sips of water followed by a fluid diet of $60 \mathrm{~mL} / \mathrm{h}$. Regular oral paracetamol and etoricoxib were given, and oral pregabalin was added to the protocol the next day. Opioid requirements were reviewed for 24 hours after surgery.

As part of the standard postoperative protocol, patients were asked to get off the bed and walk around the ward with the assistance of nursing or physiotherapy staff by the evening of the day of 
surgery. Provided there were no complications, patients were discharged on the second postoperative day. The anaesthesia protocol is summarised in Table 1.

\section{Results}

Patient characteristics are shown in Table 2, and postoperative opioid requirements are listed in Table 3.

Of the 30 patients, no opioid rescue analgesia was required in $14(46.7 \%)$ throughout the postoperative period; six (20\%) required intravenous pethidine for rescue analgesia in the PACU, but not after their return to the ward. The remaining 10 $(33.3 \%)$ patients were given intramuscular pethidine injections in the ward on request.

The mean postoperative opioid requirement per patient in the whole case series was $32 \mathrm{mg}$ of pethidine. Among the 16 patients who required rescue analgesia in the ward or in the PACU, their mean opioid requirement was $60 \mathrm{mg}$ of pethidine, with a range of 20 to $150 \mathrm{mg}$.
This anaesthetic protocol included a dexmedetomidine infusion that might cause hypotension and bradycardia due to its alpha-2 adrenoceptor blocking action. In our case series, 11 (36.7\%) patients developed transient hypotension despite intravenous fluid loading and required either intravenous ephedrine or phenylephrine. One patient had transient intra-operative bradycardia requiring atropine, probably due to preoperative use of a beta blocker and low resting heart rate.

\section{Discussion}

\section{Importance of reducing postoperative opioid use in obese patients}

Opioids are among the world's oldest known drugs. They have been used in anaesthesia traditionally as part of a balanced anaesthesia, to provide hypnosis and analgesia, to blunt the sympathetic response to surgery, and are the mainstay of postoperative analgesia in many situations. Morbidly obese patients, however, are particularly sensitive to the respiratory depressant effects of opioids. Taylor et $\mathrm{al}^{2}$ found that

TABLE I. Anaesthesia protocol

\begin{tabular}{|c|c|}
\hline Stage & Protocol \\
\hline \multirow[t]{3}{*}{ Premedication } & Pantoprazole $40 \mathrm{mg}$ po at night \\
\hline & Paracetamol $2 \mathrm{~g}$ po 2 hours before \\
\hline & Pregabalin $300 \mathrm{mg}$ po 2 hours before, reduce dose to $150 \mathrm{mg}$ if $\mathrm{BMI}<35 \mathrm{~kg} / \mathrm{m}^{2}$ or age $>60$ years \\
\hline \multirow[t]{5}{*}{ Induction } & Dexmedetomidine infusion $2 \mu \mathrm{g} / \mathrm{kg} / \mathrm{h}$ using LBW \\
\hline & Midazolam iv 1-2 mg \\
\hline & Fentanyl iv $100 \mu \mathrm{g}$ \\
\hline & Propofol iv titrated dose \\
\hline & Suxamethonium or rocuronium \\
\hline \multirow[t]{3}{*}{ Maintenance } & Desflurane titrated to keep BIS between 40 and 60 \\
\hline & Dexmedetomidine infusion $\geq 0.2 \mu \mathrm{g} / \mathrm{kg} / \mathrm{h}(\mathrm{LBW})$ \\
\hline & Rocuronium infusion to keep TOF count 1 \\
\hline \multirow[t]{4}{*}{ Intra-operative analgesia } & Ketamine bolus $0.3 \mathrm{mg} / \mathrm{kg}$ using LBW after induction, then intermittent boluses roughly equivalent to $0.2 \mathrm{mg} / \mathrm{kg} / \mathrm{h}$ \\
\hline & Parecoxib 40 mg iv after induction \\
\hline & Tramadol $100 \mathrm{mg}$ iv after induction \\
\hline & Local anaesthetic infiltration at wound closure using $0.5 \%$ levobupivacaine $20 \mathrm{~mL}$ \\
\hline Intravenous fluids & Normal saline or lactated Ringer's solution $\geq 10 \mathrm{~mL} / \mathrm{kg}$ of actual body weight \\
\hline Reversal & Neostigmine and atropine as appropriate \\
\hline \multirow[t]{2}{*}{ Rescue analgesia in PACU } & Pethidine iv $20 \mathrm{mg}$ with ketamine iv $5 \mathrm{mg}$, repeat if necessary \\
\hline & $\begin{array}{l}\text { If } 10 \mathrm{mg} \text { of ketamine has already been given, further rescue analgesia will be } 20 \mathrm{mg} \text { iv pethidine alone, repeat if } \\
\text { necessary }\end{array}$ \\
\hline \multirow[t]{3}{*}{ Routine analgesia in ward } & Extended-release paracetamol ('panadol extend') 665 mg po 3 times daily \\
\hline & Etoricoxib 120 mg po daily \\
\hline & Pregabalin $75 \mathrm{mg}$ at night from postoperative day 1 onwards \\
\hline Rescue analgesia in ward & Pethidine im 50 mg every 4 hours as required \\
\hline
\end{tabular}

Abbreviations: BIS = bispectral index; BMI = body mass index; im = intramuscular; iv = intravenous; LBW = lean body weight; PACU = post-anaesthetic care unit; po = per oral (by mouth);TOF = train-of-four 
the use of opioids per se is a risk factor for respiratory events in the first 24 hours after surgery. Ahmad et $\mathrm{al}^{1}$ demonstrated in their study of 40 morbidly obese patients who presented for laparoscopic bariatric surgery, that in using desflurane and remifentanilmorphine-based anaesthesia, hypoxaemic episodes in the first 24 hours were common, and 14 of their

TABLE 2. Patient characteristics $(n=30)$

\begin{tabular}{|c|c|}
\hline Characteristic & Data* \\
\hline \multicolumn{2}{|l|}{ Sex distribution } \\
\hline Male & 13 \\
\hline Female & 17 \\
\hline Age (years) & $41(20-64)$ \\
\hline Total body weight $(\mathrm{kg})$ & $103(70-186)$ \\
\hline Body mass index $\left(\mathrm{kg} / \mathrm{m}^{2}\right)$ & $36(27-53)$ \\
\hline Lean body weight (kg) & $59(41-82)$ \\
\hline \multicolumn{2}{|l|}{ Co-morbidities } \\
\hline Diabetes & $16(53.3)$ \\
\hline Hypertension & $15(50.0)$ \\
\hline Confirmed OSAS & $9(30.0)$ \\
\hline Ischaemic heart disease & $1(3.3)$ \\
\hline \multicolumn{2}{|l|}{ ASA class } \\
\hline I & $5(16.7)$ \\
\hline II & $24(80.0)$ \\
\hline III & $1(3.3)$ \\
\hline \multicolumn{2}{|l|}{ Duration of anaesthesia (mins) } \\
\hline All patients $(n=30)$ & $115(85-180)$ \\
\hline Sleeve gastrectomy only $(n=27)$ & $110(85-180)$ \\
\hline $\begin{array}{l}\text { Sleeve gastrectomy plus } \\
\text { cholecystectomy }(n=3)\end{array}$ & $158(145-165)$ \\
\hline
\end{tabular}

Abbreviations: ASA = American Society of Anesthesiologists; OSAS = obstructive sleep apnoea syndrome

* Data are shown in No., No. (\%), or mean (range)
40 patients had more than five hypoxic episodes per hour despite supplementary oxygen.

Another concern with use of opioids in bariatric patients is the high incidence $(>70 \%)$ of OSAS. ${ }^{7}$ In our study, $30 \%(n=9)$ of patients had OSAS confirmed by an overnight sleep study. The remaining patients were not tested although many had varying symptoms of OSAS. These untested patients were assumed to have OSAS unless proven otherwise. The American Society of Anesthesiologists recommends that in patients with OSAS, methods should be used to reduce or eliminate the requirement for systemic opioids. ${ }^{8}$ Hence, reducing perioperative opioid use by these obese patients can potentially reduce morbidity.

How can the anaesthetist avoid or reduce the use of perioperative opioids, and yet still provide balanced anaesthesia with hypnosis, analgesia, haemodynamic stability, and satisfactory postoperative analgesia? The first method is to combine general anaesthesia with regional analgesia techniques, such that anaesthetic agents will provide hypnosis while the regional blocks will provide analgesia and block sympathetic responses to surgery. Any form of major regional block in a morbidly obese patient can be technically challenging, however. Furthermore, with respect to bariatric surgery, most procedures are now performed laparoscopically, so that thoracic epidural analgesia techniques have become largely unnecessary.

Putting aside the use of regional analgesia, the second method to reduce perioperative opioid use is to use a combination of non-opioid agents with volatile agents or propofol to achieve analgesia and haemodynamic control. ${ }^{3}$ A point to note here is that as acute tolerance to the analgesic effects of opioids can rapidly develop (such as after 90 minutes of remifentanil infusion), ${ }^{9}$ any attempts to reduce postoperative opioid requirement must include an effort to either eliminate or reduce the use of intraoperative opioids. These techniques are now often described as opioid-free anaesthesia or non-opioid

TABLE 3. Postoperative opioid requirements $(n=30)$

\begin{tabular}{lc}
\hline Postoperative opioid requirement & Data* $^{*}$ \\
\hline Patients who did not require rescue opioids & $14(46.7)$ \\
\hline Patients who required rescue opioids in PACU only & $6(20.0)$ \\
\hline Patients who required rescue opioids in ward & $10(33.3)$ \\
Dose of pethidine per patient in the postoperative period $(\mathrm{mg})$ & $32(0-150)$ \\
\hline Dose of pethidine per patient in the postoperative period among those who requested $(\mathrm{mg}) \dagger$ & $60(20-150)$ \\
\hline Patients with transient intra-operative hypotension requiring treatment with vasopressors & $11(36.7)$ \\
\hline Patients with intra-operative bradycardia requiring treatment & $1(3.3)$ \\
\hline
\end{tabular}

Abbreviation: PACU = post-anaesthetic care unit

* Data are shown in No. (\%) or mean (range)

$+n=16$ 
techniques.

Paracetamol, NSAID, or COX-2 inhibitors, gabapentinoids, ketamine and alpha- 2 agonists, when used individually, have all been shown to reduce postoperative opioid requirement and improve pain relief. ${ }^{10-14}$ Different combinations of these agents, together with local anaesthetic infiltration of the wounds, have been reported for bariatric surgery, as discussed below.

\section{Development of the study protocol based on previous studies}

In 2003, Feld et $\mathrm{al}^{15}$ described a technique of using sevoflurane combined with ketorolac, clonidine, ketamine, lignocaine, and magnesium for patients undergoing open gastric bypass. Compared with the control group where sevoflurane was used with fentanyl, they found the non-opioid group to be less sedated, with less morphine use in PACU although the total morphine use at 16 hours was not significantly different to the opioid group.

In 2006 Feld et al $^{16}$ again described using desflurane combined with dexmedetomidine infusion, and compared it with a control group using desflurane and fentanyl, for patients undergoing open gastric bypass. In the dexmedetomidine group, there were lower pain scores and less morphine use in the PACU.

In 2005, Hofer et $\mathrm{al}^{17}$ described a case report of a super-obese patient weighing $433 \mathrm{~kg}$ who underwent open gastric bypass. No opioids were used but instead replaced with a high-dose dexmedetomidine infusion together with isoflurane.

As laparoscopic techniques have become more common in bariatric surgery, more studies have been carried out of non-opioid anaesthetic techniques for laparoscopic bariatric surgery. Tufanogullari et $\mathrm{al}^{18}$ described a technique in which either fentanyl or varying doses of dexmedetomidine were used with desflurane for laparoscopic bariatric surgery. All patients were also given celecoxib. Postoperatively, patients were given fentanyl boluses in PACU, then intravenous morphine via a patientcontrolled analgesia system. The only statistical difference was decreased PACU fentanyl use in the dexmedetomidine groups.

Ziemann-Gimmel et $\mathrm{al}^{19}$ looked at 181 patients undergoing laparoscopic gastric bypass. In the treatment group, volatile anaesthetics were used together with intravenous paracetamol and ketorolac. Postoperatively patients were given regular paracetamol and ketorolac. If there was breakthrough pain, intermittent oral oxycodone or intravenous hydromorphone was given. A small number of patients in this treatment group (3/89) were able to remain opioid-free throughout, and 15 patients did not require opioid medications when they were back to the ward.
In another study where the primary outcome was the incidence of PONV, Ziemann-Gimmel et $\mathrm{al}^{20}$ evaluated 119 patients undergoing laparoscopic bariatric surgery. The treatment group was managed with propofol infusion, dexmedetomidine infusion, paracetamol, ketorolac, and ketamine. The other group was managed with volatile anaesthetic and opioids. Postoperative analgesia regimen was the same as the previous study. ${ }^{19}$ They reported a large reduction in PONV in their treatment group.

While most studies reported decreased requirement of opioids for postoperative analgesia in their non-opioid groups, very few studies could achieve zero postoperative opioid use. Only Ziemann-Gimmel et $\mathrm{al}^{19}$ could achieve total opioid sparing in a small proportion (3 out of 92 patients) of the treatment group by using intra-operative and postoperative intravenous paracetamol and ketorolac.

Most of these earlier studies used a combination of only a few of the available non-opioid adjuncts. Dexmedetomidine remains a mainstay of non-opioid adjunct in most of these studies. We hence proposed the use of a wider mix of non-opioid adjuncts, using a combination of paracetamol, COX-2 inhibitor, pregabalin, ketamine, dexmedetomidine, and local anaesthesia infiltration. In contrast to the earlier studies, in our study we were able to achieve zero postoperative opioid use in a significant percentage of patients $(46.7 \%)$.

In our protocol, the only opioid given during anaesthesia was fentanyl $100 \mu \mathrm{g}$ for intubation, and tramadol $100 \mathrm{mg}$, a weak opioid, shortly after induction. All other opioid analgesics, if required, were given after the patient was awake. This avoided having to blindly give intra-operative long-acting opioids during anaesthesia, and allowed better titration of the drug by giving small boluses each time with the patient awake.

\section{Dexmedetomidine}

Dexmedetomidine was a useful agent in our protocol. Before the addition of this agent to our protocol, total opioid sparing was very difficult to achieve. Dexmedetomidine is a highly selective alpha-2 adrenoceptor blocker, with analgesic and sedative properties. ${ }^{21}$ Previous study of its use in bariatric anaesthesia has failed to show any reduction in opioid requirements. ${ }^{18}$ In our protocol, we used more non-opioid adjuncts, and since we calculated the infusion dose using LBW instead of total body weight (TBW), overall we administered a much lower dose of dexmedetomidine.

Infusion of dexmedetomidine may cause initial hypertension and tachycardia (especially during a loading dose infusion), followed by hypotension and bradycardia. In our study, no loading dose was given. Of the 30 patients, 11 (36.7\%) developed 
transient hypotension despite intravenous fluid loading and required either intravenous ephedrine or phenylephrine. This transient hypotension was also aggravated by putting the patient in a steep reverse trendelenburg position to facilitate surgical exposure, which decreases the venous return. When using dexmedetomidine in bariatric surgery, care must be taken to ensure the patient is euvolaemic.

\section{Ketamine}

Ketamine was another useful adjunct in our protocol. Ketamine is an N-methyl-D-aspartate receptor antagonist with strong analgesic properties when given at subanaesthetic doses. ${ }^{22}$ The use of ketamine has advantages in morbidly obese patients as it causes little respiratory depression compared with opioids. In our protocol, we used LBW to calculate the ketamine dose, and used relatively low ketamine doses $(0.3 \mathrm{mg} / \mathrm{kg}$ bolus followed by $0.2-0.3 \mathrm{mg} / \mathrm{kg} / \mathrm{h}$ with intermittent boluses). This resulted in a low total ketamine dose, with a mean of $31 \mathrm{mg}$ ketamine per patient (range, 25-50 mg). Midazolam 1 to $2 \mathrm{mg}$ was also given at induction to prevent any psychomimetic reactions caused by ketamine. No patient developed any hallucinations or dysphoria and there was no delay in emergence noted in our patients.

\section{The use of lean body weight as dosing scalar}

In our protocol, we chose to use LBW to calculate the dose for dexmedetomidine and ketamine. The classic teaching is that for obese patients, anaesthetic drugs can be dosed according to the TBW versus ideal body weight or LBW according to lipid solubility. Lipophilic drugs are better dosed according to actual body weight due to an increase in volume of distribution, whereas hydrophilic drugs are better dosed according to LBW or ideal body weight. ${ }^{23}$ Lean body weight is significantly correlated with cardiac output, and drug clearance increases proportionately with $\mathrm{LBW}{ }^{6}$

There is insufficient information regarding the pharmacokinetics and pharmacodynamics of dexmedetomidine and ketamine in the morbidly obese patient. In the few previous studies regarding dexmedetomidine and bariatric anaesthesia, TBW was used as dosing scalars. For example, Feld et $\mathrm{al}^{16}$ used $0.5 \mu \mathrm{g} / \mathrm{kg}$ TBW loading dose followed by $0.4 \mu \mathrm{g} / \mathrm{kg} / \mathrm{h}$ infusion in their series of 10 patients with open gastric bypass. Ziemann-Gimmel et $\mathrm{al}^{20}$ used $0.5 \mu \mathrm{g} / \mathrm{kg}$ TBW loading dose followed by 0.1 to $0.3 \mu \mathrm{g} / \mathrm{kg} / \mathrm{h}$ infusion for their group of 60 patients undergoing a variety of bariatric procedures. Tufanogullari et $\mathrm{al}^{18}$ gave no loading dose and infused from 0 to $0.8 \mu \mathrm{g} / \mathrm{kg} / \mathrm{h}$ in their series of 80 patients undergoing laparoscopic banding or bypass. There were little data regarding ketamine dose in bariatric surgery. We chose to dose these two drugs using LBW to see how our results would differ from the other published studies.

\section{Limitations of the study}

Our study has several limitations. It was a prospective observational study with a relatively small number of cases. We do not have data to compare this protocol with our previous protocols, nor do we have data in the form of a randomised controlled trial to look at the isolated effect of any of the drugs used.

The opioid that we used for rescue analgesia was pethidine, given intravenously in the recovery room by the anaesthetist, or given intramuscularly on the ward by the nurses upon standing order. One can argue that the mean opioid dose per patient was not accurate as some were given small intravenous boluses and others were given intramuscular injections of fixed dose. To accurately assess the postoperative parenteral opioid requirements in theory, all patients should be given a patientcontrolled analgesia system to deliver boluses of parenteral opioids as required. This, however, is not practical and not necessary for the patient, given that two thirds of our patients did not require any opioids at all. This would also represent a lot of drug wastage when the whole cassette of drugs was unused.

We were able to demonstrate that a significant proportion of patients did not require any opioids, but we do not have data to demonstrate a reduction in respiratory complications or an improvement in time to ambulation or discharge. This could be the basis for further studies.

\section{Declaration}

All authors have disclosed no conflicts of interest.

\section{References}

1. Ahmad S, Nagle A, McCarthy RJ, et al. Postoperative hypoxaemia in morbidly obese patients with and without obstructive sleep apnea undergoing laparoscopic bariatric surgery. Anesth Analg 2008;107:138-43.

2. Taylor S, Kirton OC, Staff I, Kozol RA. Postoperative day one: a high risk period for respiratory events. Am J Surg 2005;190:752-6.

3. Mulier JP. Perioperative opioids aggravate obstructive breathing in sleep apnea syndrome: mechanisms and alternative anaesthesia strategies. Curr Opin Anaesthesiol 2016;29:129-33.

4. Alvarez A, Singh PM, Sinha AC. Postoperative analgesia in morbid obesity. Obes Surg 2014;24:652-9.

5. Hume R. Prediction of lean body mass from height and weight. J Clin Pathol 1966;19:389-91.

6. Ingrande J, Lemmens HJ. Dose adjustment of anaesthetics in the morbidly obese. Br J Anaesth 2010;105 Suppl 1:i1623.

7. Lopez PP, Stefan B, Schulman CI, Byers PM. Prevalence of sleep apnea in morbidly obese patients who presented for weight loss surgery evaluation: more evidence for routine screening for obstructive sleep apnea before weight loss 
surgery. Am Surg 2008;74:834-8.

8. American Society of Anesthesiologists Task Force on Perioperative Management of patients with obstructive sleep apnea. Practice guidelines for the perioperative management of patients with obstructive sleep apnea: an updated report by the American Society of Anesthesiologists Task Force on Perioperative Management of patients with obstructive sleep apnea. Anesthesiology 2014;120:268-86.

9. Vinki HR, Kissin I. Rapid development of tolerance to analgesia during remifentanil infusion in humans. Anesth Analg 1998;86:1307-11.

10. Dahl JB, Nielsen RV, Wetterslev J, et al. Post-operative analgesic effects of paracetamol, NSAIDs, glucocorticoids, gabapentinoids and their combinations: a topical review. Acta Anaesthesiol Scand 2014;58:1165-81.

11. Blaudszun G, Lysakowski C, Elia N, Tramèr MR. Effect of perioperative systemic $\alpha 2$ agonists on postoperative morphine consumption and pain intensity: systematic review and meta-analysis of randomized controlled trials. Anesthesiology 2012;116:1312-22.

12. Cabrera Schulmeyer MC, de la Maza J, Ovalle C, Farias C, Vives I. Analgesic effects of a single preoperative dose of pregabalin after laparoscopic sleeve gastrectomy. Obes Surg 2010;20:1678-81.

13. Weinbroum AA. Non-opioid IV adjuvants in the perioperative period: pharmacological and clinical aspects of ketamine and gabapentinoids. Pharmocol Res 2012;65:411-29.

14. Alimian M, Imani F, Faiz SH, Pournajafian A, Navadegi SF, Safari S. Effect of oral pregabalin premedication on post-operative pain in laparoscopic gastric bypass surgery. Anesth Pain Med 2012;2:12-6.
15. Feld JM, Laurito CE, Beckerman M, Vincent J, Hoffman WE. Non-opioid analgesia improves pain relief and decreases sedation after gastric bypass surgery. Can J Anaesth 2003;50:336-41.

16. Feld JM, Hoffam WE, Stechert MM, Hoffman IW, Anada RC. Fentanyl or dexmedetomidine combined with desflurane for bariatric surgery. J Clin Anesth 2006;18:24-8.

17. Hofer RE, Sprung J, Sarr MG, Wedel DJ. Anesthesia for a patient with morbid obesity using dexmedetomidine without narcotics. Can J Anaesth 2005;52:176-80.

18. Tufanogullari B, White PF, Peixoto MP, et al. Dexmedetomidine infusion during laparoscopic bariatric surgery: the effect on recovery outcome variables. Anesth Analg 2008;106:1741-8.

19. Ziemann-Gimmel P, Hensel P, Koppman J, Marema R. Multimodal analgesia reduces narcotic requirements and antiemetic rescue medication in laparoscopic Roux-en-Y gastric bypass surgery. Surg Obes Relat Dis 2013;9:975-80.

20. Ziemann-Gimmel P, Goldfarb AA, Koppman J, Marema RT. Opioid-free total intravenous anaesthesia reduces postoperative nausea and vomiting in bariatric surgery beyond triple prophylaxis. Br J Anaesth 2014;112:906-11.

21. Carollo DS, Nossaman BD, Ramadhyani U. Dexmedetomidine: a review of clinical applications. Curr Opin Anaesthesiol 2008;21:457-61.

22. Gammon D, Bankhead B. Perioperative pain adjuncts. In: Johnson KB, editor. Clinical pharmacology for anesthesiology. McGraw-Hill Education; 2014: 157-78.

23. Sinha AC, Eckmann DM. Anesthesia for bariatric surgery. In: Miller RD, Eriksson LI, Fleisher LA, Wiener-Kronish JP, Young WL, editors. Miller's anesthesia. 7th ed. Philadelphia: Churchill Livingston; 2015: 2089-104. 